\title{
Population Genetic Analysis of an Eastern U.S. Wheat Powdery Mildew Population Reveals Geographic Subdivision and Recent Common Ancestry with U.K. and Israeli Populations
}

\author{
Ryan Parks, Ignazio Carbone, J. Paul Murphy, and Christina Cowger
}

First and fourth authors: United States Department of Agriculture-Agricultural Research Service, Department of Plant Pathology, second author: Department of Plant Pathology, and third author: Department of Crop Science, North Carolina State University, Raleigh 27695. Accepted for publication 2 March 2009.

\begin{abstract}
Parks, R., Carbone, I., Murphy, J. P., and Cowger, C. 2009. Population genetic analysis of an eastern U.S. wheat powdery mildew population reveals geographic subdivision and recent common ancestry with U.K. and Israeli populations. Phytopathology 99:840-849.

The structure of the U.S. wheat powdery mildew population (Blumeria graminis f. sp. tritici) has not been previously investigated, and the global evolutionary history of B. graminis f. sp. tritici is largely unknown. After gathering 141 single-ascosporic B. graminis f. sp. tritici isolates from 10 eastern U.S. locations, 34 isolates from the United Kingdom, and 28 isolates from Israel, we analyzed pathogen population structure using presumptively neutral markers. DNA was extracted from conidia, primers for 12 "housekeeping" genes were designed, and amplicons were examined for polymorphism. Four genes were found to contain a total of 12 single-nucleotide polymorphisms in the U.S. population and were also

analyzed in the U.K. and Israeli populations. In total, 25 haplotypes were inferred from the four concatenated genes, with 2 haplotypes comprising over $70 \%$ of the U.S. population. Using Hudson's tests and analysis of molecular variance, we found the wheat mildew isolates subdivided into four groups corresponding to distinct regions: the mid-Atlantic United States, the southern United States, the United Kingdom, and Israel. Genotypic diversity was greatest in samples from the United Kingdom, Israel, Virginia, and Kinston, NC. Using rarefaction, a procedure that compensates for differing sample sizes when estimating population richness and diversity, we found that cooler locations with greater conduciveness to regular powdery mildew epidemics had the greatest haplotype richness. Our results suggest that the eastern U.S. B. graminis f. sp. tritici population is young, descended recently from Old World populations with isolation and genetic drift, and is currently subdivided into northern and southern subpopulations.
\end{abstract}

Native to the Middle East, wheat (Triticum aestivum) is among the world's oldest cultivated plants and was widely spread by humans (70). Wheat was first grown in the United States in 1602 off the southern coast of Massachusetts (19), and was first cultivated in Virginia in 1611 (17). Around the same time, Spanish settlers also introduced wheat to Mexico (17).

The biotrophic filamentous ascomycete Blumeria graminis (DC.) Speer f. sp. tritici (Em. Marchal) causes powdery mildew of wheat $(27,42,44,77)$. Due to the specialized nature of the hostpathogen relationship, mildews parasitic to one host species generally cannot grow on another $(39,52,53,64,73,93)$, and $B$. graminis is divided into eight formae speciales (36) that are distinguished by their host interactions. In recent times, the U.S. region most consistently favorable in terms of climate for regular wheat powdery mildew epidemics encompasses Maryland, Virginia, and North Carolina. Although the origins and history of modern hexaploid wheat in the United States are generally understood $(12,17,94)$, the population structure of B. graminis $\mathrm{f}$. sp. tritici remains understudied.

Previous studies of wheat powdery mildew population structure have consisted of virulence surveys $(38,44,45,47,55,58,59,61$, $76,83,88,92)$. Due to host selection for virulence alleles and geographic variability in the deployment of resistance genes $(\mathrm{Pm}$ genes), powdery mildew virulence gene frequencies are of limited

Corresponding author: R. Parks; E-mail address: wrparks@ncsu.edu

doi:10.1094/PHYTO-99-7-0840

This article is in the public domain and not copyrightable. It may be freely reprinted with customary crediting of the source. The American Phytopathological Society, 2009. use in inferring population structure and offer no insights into historical structuring processes.

In population analysis, electrophoretically derived markers such as amplified fragment length polymorphisms (AFLPs) (93) are useful for identification of strains or races; however, these markers have limited phylogenetic utility because shared bands do not necessarily indicate common ancestry (48). Polymorphisms such as single-nucleotide polymorphisms (SNPs) in DNA sequences can be utilized in more complex population genetic models to draw statistical inferences about historical processes structuring modern populations $(41,65,85)$. These data also allow for a phylogeographic approach to investigating population structure $(4,5,8,86,87)$. Using a combination of methods, more accurate inferences can be made concerning contemporary and historical processes structuring the wheat powdery mildew population $(2,9)$.

Wheat powdery mildew undergoes multiple secondary cycles of asexual conidial reproduction each growing season (92). As temperatures rise at the end of the growing season, compatible mating types form chasmothecia (cleistothecia, or sexual fruiting bodies) $(28,42,92)$. Both ascospores and conidia are wind dispersed (92). Long-distance dispersal is known for biotrophic pathogens that produce copious secondary inoculum and is believed to account for the transmission of novel virulences in $B$. graminis f. sp. hordei (the barley powdery mildew pathogen) from continental Europe to Britain (10). Transport of viable barley mildew spores across the North Sea from Britain to Denmark, a distance of $\approx 800 \mathrm{~km}$, has been demonstrated (32).

Given what is known about the arrival of wheat in North America, it seems likely that $B$. graminis f. sp. tritici was first introduced to the continent less than 500 years ago. Alternatively, B. graminis f. sp. tritici in North America could have originated 
on native wild grass species and evolved pathogenicity to T. aestivum. At least three Elymus and Hordeum spp. are native to North America (78) and have been reported as B. graminis hosts (80). Although it seems more likely that mildew was introduced into the United States at some point in the recent past, it is unknown how many founder events occurred or whether gene flow between continents is still occurring. Due to the ephemeral nature of mildew spores $(15,18)$, wind dispersal over the Atlantic Ocean between Europe and the United States seems improbable. However, the possibility of ongoing gene flow via human-aided spore transport cannot be excluded.

Possible gene flow due to long-distance dispersal is compatible with the possibility of regional differentiation of the B. graminis $\mathrm{f}$. sp. tritici population within the United States. Large-scale spore dispersal with unknown rates of gene flow suggests a need for sampling wheat mildew at varying geographic scales $(3,23,83)$. Previous studies based on virulence frequencies indicated regional clustering of B. graminis f. sp. tritici virulence phenotypes

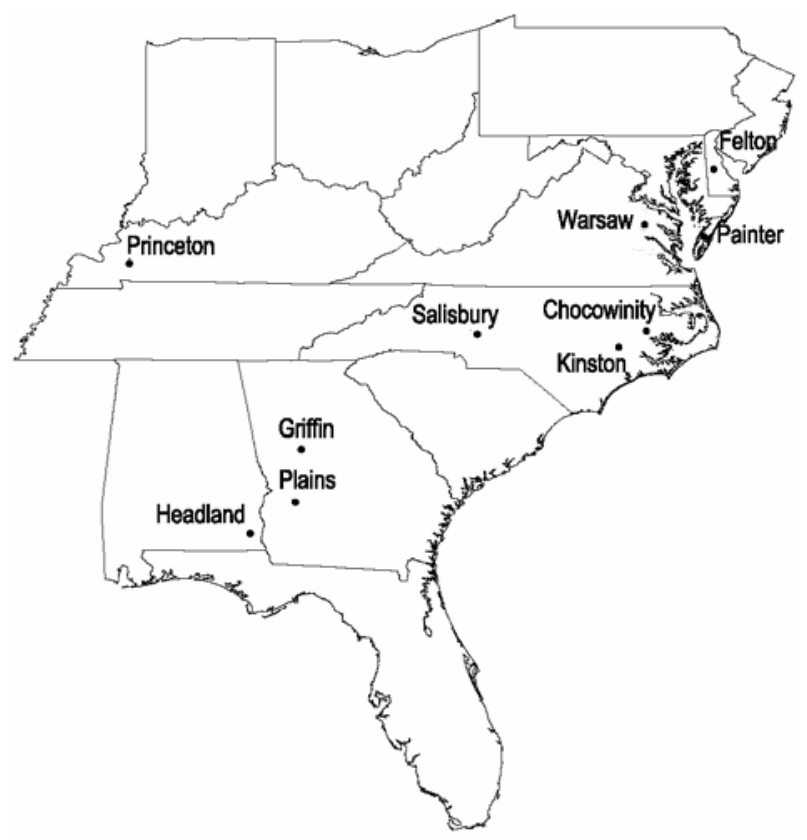

Fig. 1. U.S. locations where wheat leaves infected with powdery mildew were collected in 2003 and 2005: Chocowinity, NC; Felton, DE; Griffin, GA; Headland, AL; Kinston, NC; Painter, VA; Plains, GA; Princeton, KY; Salisbury, NC; and Warsaw, VA.
$(44,59)$; however, such clustering may result from regional cultivar preferences rather than from restricted gene flow.

To analyze the population structure of U.S. wheat mildew, a collection of 206 single-ascosporic isolates was sampled from 10 southeastern U.S. locations. By virulence frequencies, these isolates generally clustered into north and south groups, as previously reported (59). For comparison, smaller numbers of $B$. graminis f. sp. tritici isolates were obtained from the United Kingdom and Israel. We chose these locations as presumably more ancient reservoirs for the wheat-mildew pathosystem, because wheat has been cultivated for $\approx 10,000$ years in the Middle East (70) and $\approx 4,000$ years in Great Britain (69). Further, collections of mildew isolates were available from the United Kingdom and Israel but not immediately from other potential sources of immigration-associated introductions to the United States, such as Spain.

In this study, we used selectively neutral markers to test two hypotheses. First, we hypothesized that $B$. graminis f. sp. tritici isolates would demonstrate north-south clustering within the eastern United States, and that a larger difference would be found between the U.S. population and the putatively ancestral populations of the United Kingdom and Israel. Second, we hypothesized that "Old World" B. graminis f. sp. tritici populations would exhibit higher levels of sequence polymorphism than U.S. populations. We chose SNPs in "housekeeping" genes rather than AFLPs partly for reasons discussed above, but also because it would have been excessively time-consuming to generate the larger amounts of DNA required by the latter technique, as the DNA was extracted from the conidia of an obligate pathogen.

\section{MATERIALS AND METHODS}

Mildew isolates. $B$. graminis f. sp. tritici isolates from the United States were derived from wheat leaves supplied by cooperators in six states as previously described: Delaware, Kentucky, Virginia, North Carolina, Georgia, and Alabama (59) (Fig. 1). The locations were representative of those conducive to mildew in 2003 and 2005, and the leaves were collected in research plots of highly susceptible cultivars in order to preclude bias in isolate sampling from the selective influence of varying resistance genes. Usually, multiple leaves with abundant cleistothecia were sampled from each plot, and several plots were sampled per field when possible. Therefore, the samples were assumed to be an unbiased reflection of the population present in the field. The numbers of field plots and leaves giving rise to each sample are listed in Table 1 . To assess possible clonality among

TABLE 1. Molecular diversity indices and sampling information on Blumeria graminis f. sp. tritici isolates from the eastern United States, the United Kingdom, and Israel

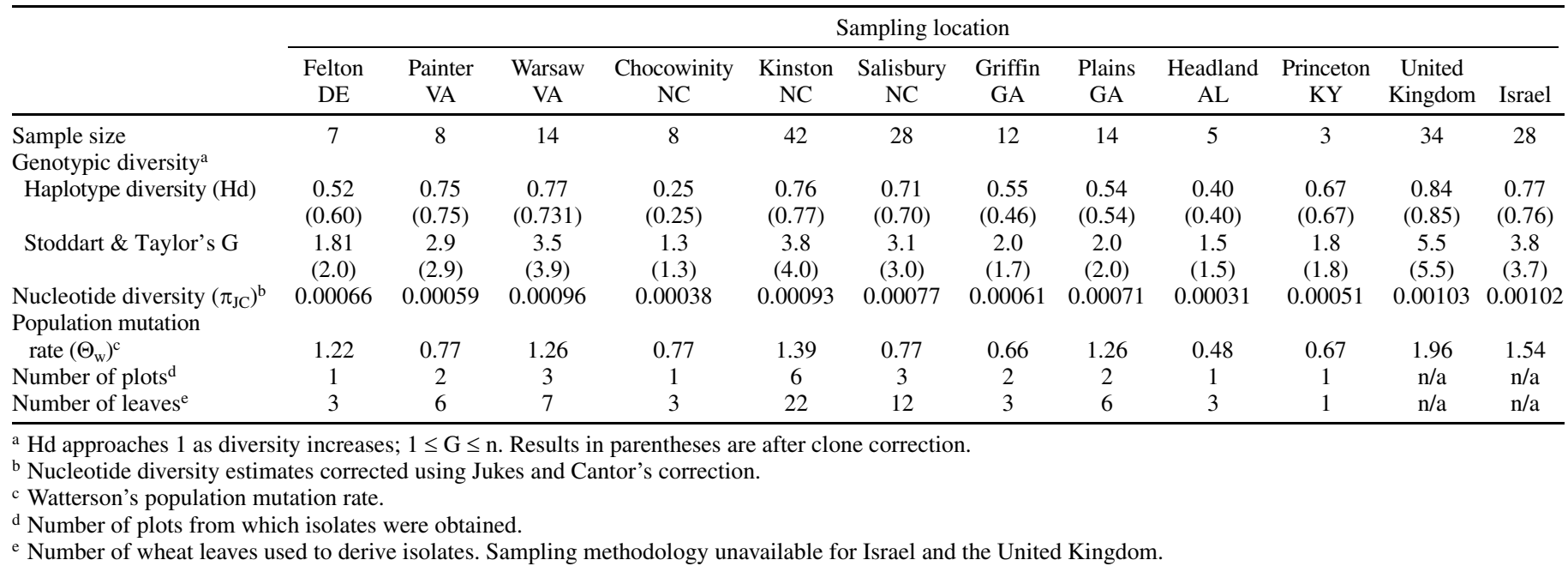


isolates from a location, which sometimes originated from the same leaf, we determined that 40 to $85 \%$ of isolates possessed a multilocus virulence phenotype unique to their field plot (59). Possession of the same multilocus virulence phenotype does not, of course, prove clonality.

Single-ascospore isolates for all samples originating in the United States were derived by suspending cleistothecia-laden leaves above detached leaves of the universally susceptible common wheat cv. Chancellor, floating on benzimidazole agar in petri plates

TABLE 2. Sampling location, wheat species, and cultivar for Blumeria graminis f. sp. tritici isolates collected in the United Kingdom and Israel

\begin{tabular}{|c|c|c|c|}
\hline Isolate & Sampling location & Host (Triticum spp.) & Cultivar \\
\hline IS-103 & Ami'ad & $\operatorname{diccoc}$ & $\ldots$ \\
\hline IS-70 & Be'eri & aestivum & Deganit \\
\hline IS-25 & Bet Dagan & durum & Inbar \\
\hline IS-68 & Bet Dagan & aestivum & BetHashita \\
\hline IS-20 & Ein HaNaziv & durum & Inbar \\
\hline IS-94 & Ein HaNaziv & aestivum & Deganit \\
\hline IS-1 & Hula & aestivum & Dari'el \\
\hline IS-13 & Hula & aestivum & 509 \\
\hline IS-4 & Hula & aestivum & Deganit \\
\hline IS-6 & Hula & aestivum & Atir \\
\hline IS-7 & Hula & aestivum & Shafir \\
\hline IS-8 & Hula & durum & Bareket \\
\hline IS-9 & Hula & aestivum & 652 \\
\hline IS-67 & Lahav & durum & Inbar \\
\hline IS-106 & Nahal Oz & aestivum & Atir \\
\hline IS-108 & Nahal Oz & durum & Bareket \\
\hline IS-16 & Nahal Oz & durum & Inbar \\
\hline IS-37 & Nahal Oz & aestivum & Deganit \\
\hline IS-96 & Negba & aestivum & sw50 \\
\hline IS-44 & Negev & aestivum & Miriam \\
\hline IS-47 & Sa'ad & aestivum & BetLehem \\
\hline IS-91 & Sde Eliyahu & durum & Inbar \\
\hline IS-30-1P & Talmei yafe & aestivum & Shafir \\
\hline IS-30-2W & Talmei yafe & aestivum & Shafir \\
\hline IS-92 & Tel Aviv & dicoccoides & \\
\hline IS-15 & Yavor & durum & Inbar \\
\hline IS-43 & Yesodot & aestivum & BetHashita \\
\hline IS-113 & $\ldots$ & $\ldots$ & W-B-1 \\
\hline WM-A-12 & Bedfordshire & aestivum & Cerco \\
\hline WM-A-2 & Bedfordshire & aestivum & Cerco \\
\hline WM-A-6 & Bedfordshire & aestivum & Cerco \\
\hline WM-77-1 & Herefordshire & aestivum & Timber \\
\hline WM-59-3 & Northern Ireland & aestivum & Cordiale \\
\hline WM-59-4 & Northern Ireland & aestivum & Cordiale \\
\hline WM-60-2 & Northern Ireland & aestivum & Claire \\
\hline WM-60-3 & Northern Ireland & aestivum & Claire \\
\hline WM-62-2 & Northern Ireland & aestivum & Humber \\
\hline WM-63-1 & Northern Ireland & aestivum & Sahara \\
\hline WM-64-1 & Northern Ireland & aestivum & Robigus \\
\hline WM-67-1 & Northern Ireland & aestivum & Brompton \\
\hline WM-69-2 & Northern Ireland & aestivum & Challenger \\
\hline WM-41-5 & Suffolk & aestivum & Haven \\
\hline WM-42-6 & Suffolk & aestivum & Hobbit \\
\hline WM-43-1 & Suffolk & aestivum & Claire \\
\hline WM-44-3 & Suffolk & aestivum & Vuka \\
\hline WM-44-5 & Suffolk & aestivum & Vuka \\
\hline WM-RAB-31 & Suffolk & aestivum & Cerco \\
\hline WM-RAB-32 & Suffolk & aestivum & Cerco \\
\hline WM-RAB-38 & Suffolk & aestivum & Cerco \\
\hline WM-RAB-44 & Suffolk & aestivum & Cerco \\
\hline WM-RAB-57 & Suffolk & aestivum & Cerco \\
\hline WM-RAB-62 & Suffolk & aestivum & Cerco \\
\hline WM-RAB-69 & Suffolk & aestivum & Cerco \\
\hline WM-1-1 & Warwickshire & aestivum & Glasgow \\
\hline WM-14-5 & Warwickshire & aestivum & Timber \\
\hline WM-16-1 & Warwickshire & aestivum & Brompton \\
\hline WM-18-1 & Warwickshire & aestivum & Claire \\
\hline WM-18-2 & Warwickshire & aestivum & Claire \\
\hline WM-3-3 & Warwickshire & aestivum & Robigus \\
\hline WM-7-2 & Warwickshire & aestivum & Challenger \\
\hline WM-7-3 & Warwickshire & aestivum & Challenger \\
\hline WM-79-3 & Yorkshire & aestivum & Alchemy \\
\hline
\end{tabular}

incubated in a growth chamber at $17^{\circ} \mathrm{C}(59)$. Colonies were isolated from the resulting single-ascospore infections. Isolates included in the present report are that subset of the population previously described (59) for which polymerase chain reaction (PCR) amplicons could be sequenced at all polymorphic DNA positions.

Isolates from the United Kingdom (Table 2) were kindly furnished by Dr. Rosemary Bayles, National Institute of Agricultural Botany, Cambridge, UK. Single-spored B. graminis f. sp. tritici isolates were derived from 14 common wheat cultivars grown commercially in six counties as part of the 2006 United Kingdom Cereal Pathogen Virulence Survey.

Dr. Amos Dinoor (Hebrew University of Jerusalem, Rehovot, Israel) kindly provided B. graminis f. sp. tritici isolates obtained from three Triticum spp. (aestivum, durum, and dicoccum) in 15 Israeli locations (Table 2). These isolates were part of a larger collection of the late Dr. Nava Eshed and, at the time of our study, had been maintained in Israel for 15 to 20 years on detached Triticum leaves floated on benzimidazole agar.

DNA extraction. Conidia were collected by dipping 10 to 20 $2-\mathrm{cm}$ detached leaf pieces with large, fluffy colonies of mildew into a microfuge tube with $1.5 \mathrm{ml}$ of $95 \%$ ethanol to disrupt hydrophobic interactions and allow conidia to enter solution. Microcentrifuge tubes were centrifuged for $\approx 20 \mathrm{~s}$ at $14,000 \mathrm{rpm}$ and the ethanol was decanted, leaving a pellet of conidia which was air dried and then frozen at $-80^{\circ} \mathrm{C}$ until DNA extraction.

DNA was extracted using a Qiagen DNeasy Blood and Tissue kit (Qiagen, Valencia, CA) and following the spin column protocol for animal tissue with slight modifications. Modifications included adding $\approx 25 \mathrm{mg}$ of sand to the microcentrifuge tubes and grinding by hand for $\approx 1 \mathrm{~min}$ in the presence of liquid nitrogen with a pellet pestle. Once conidia were sufficiently ground, the Qiagen protocol was begun at step 1 with the addition of buffer ATL. After the addition of proteinase K, samples were incubated at $65^{\circ} \mathrm{C}$ for $20 \mathrm{~min}$. Prior to addition of cell lysate to columns, $30 \mu \mathrm{l}$ of $3 \mathrm{M}$ sodium acetate ( $\mathrm{pH}$ 5) was added to ensure sample binding. DNA yields were 1,000 to $10,000 \mathrm{ng}$.

Primer design, DNA amplification, and sequencing. Candidate regions to be screened as population markers were identified in GenBank by searching for B. graminis f. sp. tritici and $B$. graminis f. sp. hordei genes. Protein-coding genes were chosen because of the faster rate of evolution when compared with rDNA (36). Sequences from GenBank were input into Primer3 (67) for primer design. For sequences with introns defined in GenBank, Primer3 was instructed to select regions spanning at least one intron in order to increase the likelihood of detecting polymorphisms (13).

PCR was carried out in $20-\mu \mathrm{l}$ volumes and all primers amplified under identical thermal cycling conditions and reagent concentrations, except the primers for protein phosphatase type $2 \mathrm{~A}$ (PPA), which ran at an annealing temperature of $61^{\circ} \mathrm{C}$. Each reaction contained $2 \mu \mathrm{l}$ of Bioline $10 \times$ Buffer $\left(160 \mathrm{mM}\left(\mathrm{NH}_{4}\right)_{2} \mathrm{SO}_{4}\right.$, $670 \mathrm{mM}$ Tris- $\mathrm{HCl}, 0.1 \%$ Tween-20), $3.0 \mathrm{mM} \mathrm{MgCl} 2,0.3125 \mathrm{mM}$ dNTPs, $0.8 \mu \mathrm{M}$ each primer, 1.5 units of Biolase Taq DNA polymerase (Bioline USA, Boston), and $\approx 20 \mathrm{ng}$ of genomic DNA. The cycling conditions were one cycle of $96^{\circ} \mathrm{C}$ for $5 \mathrm{~min}$; then 34 cycles of $96^{\circ} \mathrm{C}$ for $25 \mathrm{~s}, 55^{\circ} \mathrm{C}$ for $25 \mathrm{~s}$, and $72^{\circ} \mathrm{C}$ for $45 \mathrm{~s}$; followed by a final extension step of $72^{\circ} \mathrm{C}$ for $5 \mathrm{~min}$. Prior to sequencing, unincorporated dNTPs, salts, and primers were removed using either the QIAquick PCR purification kit or the QuickStep2 96-well PCR purification kit (Edge BioSystems, Gaithersburg, MD). Sequencing was carried out at the DNA Facility of the Iowa State University Office of Biotechnology. In total, 12 protein-coding regions were amplified and sequenced (Table 3). Sequence alignment and manual editing of base calls were carried out with Sequencher 4.7 (Gene Codes Corporation, Ann Arbor, MI).

Population structure analysis. All population analyses except analysis of molecular variance (AMOVA) and rarefaction were 
carried out using SNAP Workbench 2.0, an implementation of multiple evolutionary analysis applications under a single interface (62). Within the Workbench, analysis followed the flowchart outlined by Carbone et al (14).

Tests for neutrality determine whether observed genetic variation is consistent with the hypothesis that the majority of polymorphisms contributing genetic variability are selectively neutral (40). Tajima's $D$ (84); Fu and Li's $D, F, D s$, and $F s$ (26); and Fu's Fs (25) neutrality statistics were computed using NeutralityTest (62). Neutrality statistics were tested for an excess of recent mutations or rare alleles (left-side test) and excess of ancient mutations (right-side test). Tests for linkage disequilibrium (LD) are used to detect the nonrandom association of alleles at different loci (46,74). LD was assessed using MultiLocus 1.2 (1), with each haplotype within a gene considered an allele at that locus. Significance was assessed using 1,000 randomizations of the data set to create a null distribution.

Genotypic diversity at each sampling location was estimated by calculating haplotype diversity $(\mathrm{Hd})(7,56)$ using DnaSP version 4.0 (66) and by manual calculation of Stoddard and Taylor's G (81). Genotypic diversity estimates are susceptible to sampling error bias if a large number of clones are sampled. Isolates were considered clones if they were derived from a single leaf, had identical virulence phenotypes, and had identical multilocus sequence haplotypes. Putative clones were corrected such that one representative of each clone remained. Genotypic diversity was then calculated on both the complete data set and the clonecorrected data set. In addition, Watterson's population mutation rate $\left(\theta_{\mathrm{w}}\right)$ was estimated (89) and nucleotide diversity was calculated with Jukes and Cantor's correction $\left(\pi_{\mathrm{JC}}\right)(49)$.

Genotype diversity estimates comprise both richness and evenness. Richness is a measure of the estimated number of genotypes in a population and evenness measures the distribution of genotypes. Most diversity estimates combine richness and evenness, which is appropriate as long as sample sizes are similar. To address inequality in sample sizes, rarefaction curves have been employed to estimate the number of genotypes expected to be sampled in a population of $n$ individuals $(29,30,43)$. Tests of richness estimated by rarefaction curves were performed using rarefac.C (30). For a given population, rarefac.C estimates the expected number of sampled genotypes for samples of size 1 to $N$. This estimator is $\mathrm{E}\left(\mathrm{g}_{\mathrm{n}}\right)$, and the curve obtained from the population with the largest size can be used to predict the number of genotypes expected to be found in a sample of $n$ individuals (72). The slope of the rarefaction curve can be used to infer the rate of genotype accumulation, with steeper slopes indicating greater richness (37). Locations with sample sizes $<10$ were omitted from the rarefaction analysis.

Phylogenetic analyses based on haplotypes were performed using maximum likelihood (ML) and maximum parsimony (MP) heuristic searches in PAUP* (60). MP methods infer phylogenetic relationships by attempting to find the tree that uses the minimum number of mutations to explain the relationship among taxa (31). ML uses probabilistic, model-based methods to find the phylogeny most likely for the given data set (24). Because the ancestral haplotype was unknown, neither ML or MP searches had an outgroup defined. In addition, support for the ML phylogeny was assessed using 500 bootstrap replications within PAUP*.

Phylogenetic conflict may arise when multilocus sequence data are combined, because individual gene genealogies may have distinct and incompatible evolutionary histories. Conflict can also arise due to multiple mutations at the same site (50). Conflicting genealogies result in multiple equally likely trees and phylogenetic uncertainty, limiting the analyses that can be performed on a data set (82). The four-gamete test defines as incompatible pairs of sites where all four binary allele combinations are present, because the four states cannot be represented in a single bifurcating genealogy (e.g., if AT, AA, TT, and TA are all found in the same sample, the two base positions would be incompatible) (34). Incompatible sites were removed using SNAP CladeEx (79). Removing incompatible sites reduced the total number of polymorphisms for phylogenetic inference but was necessary for examining population history using the coalescent analyses in SNAP Workbench, such as the migration analysis software MDIV (57), that assume an absence of incompatible sites.

TABLE 3. Primers used as markers for the detection of single-nucleotide polymorphisms in the eastern U.S. Blumeria graminis f. sp. tritici population

\begin{tabular}{|c|c|c|c|c|c|c|c|}
\hline Locus & Gene product & $\begin{array}{c}\text { Source } \\
\text { accession no. }\end{array}$ & Host & Primer & Primer sequence $5^{\prime}-3^{\prime}$ & $\begin{array}{l}\text { Product } \\
\text { size (bp) }\end{array}$ & Variability $^{\mathrm{a}}$ \\
\hline $\mathrm{AOX}^{\mathrm{b}}$ & Alternative oxidase & AF327336 & Barley & $\begin{array}{l}\text { AOX361F } \\
\text { AOX589R }\end{array}$ & $\begin{array}{l}\text { TACGTCCGTTTTCATCGACA } \\
\text { GGGCTATGCGATCTGAGAAG }\end{array}$ & 220 & Polymorphic \\
\hline AQU & Aquaporin & AJ544064 & Barley & $\begin{array}{l}\text { AQU870F } \\
\text { AQU1189R }\end{array}$ & $\begin{array}{l}\text { GACATCCGTGAAGCAAGGTT } \\
\text { TAAGACTGCACCTGCGATTG }\end{array}$ & 320 & Monomorphic \\
\hline $\mathrm{BEK}$ & Mitogen-activated protein kinase kinase & AJ304830 & Unknown & $\begin{array}{l}\text { BEK180F } \\
\text { BEK1154R }\end{array}$ & $\begin{array}{l}\text { GGATTTGAAGCGGGAAGAC } \\
\text { TGAGACCTACAGCCCATTCC }\end{array}$ & 975 & Monomorphic \\
\hline CAT & Catalase & AF327335 & Barley & $\begin{array}{l}\text { CAT433F } \\
\text { CAT1129R }\end{array}$ & $\begin{array}{l}\text { AGACCAATTCAAGGTCGAAGA } \\
\text { TGAAGAGTGGATGGCTGTTG }\end{array}$ & 700 & Monomorphic \\
\hline CHD & Chitin deacetylase & AY039008 & Unknown & $\begin{array}{l}\text { CHD2044F } \\
\text { CHD2383R }\end{array}$ & $\begin{array}{l}\text { CTCCGGATTGTCAATTTCGT } \\
\text { CCATGGAAGATTAGCCGTGT }\end{array}$ & 340 & Monomorphic \\
\hline CPX & Catalase/peroxidase & AF329396 & Barley & $\begin{array}{l}\text { CPX56F } \\
\text { CPX1205R }\end{array}$ & $\begin{array}{l}\text { CGCACAAACTTGGTGTATTA } \\
\text { TCCCAATCGTATTTGAAGAG }\end{array}$ & 1,150 & Monomorphic \\
\hline $\mathrm{PKA}^{\mathrm{c}}$ & Protein kinase $\mathrm{A}$ & AF283106 & Barley & $\begin{array}{l}\text { PKA510F } \\
\text { PKA1467R }\end{array}$ & $\begin{array}{l}\text { TTTCGGTAGGGTTCATCTGG } \\
\text { TACCGTTCCGTCTCTTCAGG }\end{array}$ & 958 & Polymorphic \\
\hline $\mathrm{PKC}$ & Protein kinase $\mathrm{C}$ & AF247001 & Barley & $\begin{array}{l}\text { PKC201F } \\
\text { PKC993R }\end{array}$ & $\begin{array}{l}\text { AAGAGCTTCAGATGCGTAAG } \\
\text { CGACCCTTATGGTTACAAAA }\end{array}$ & 793 & Monomorphic \\
\hline $\mathrm{PPA}^{\mathrm{d}}$ & Protein phosphatase type $2 \mathrm{~A}$ & AF462042 & Unknown & $\begin{array}{l}\text { PPA252F } \\
\text { PPA1010R }\end{array}$ & $\begin{array}{l}\text { TAGATGGGTGGATTGAGAAC } \\
\text { ATCGTCAGGATCAGACCATA }\end{array}$ & 759 & Polymorphic \\
\hline PTH & Integral membrane protein & AF329397 & Barley & $\begin{array}{l}\text { PTH671F } \\
\text { PTH1479R }\end{array}$ & $\begin{array}{l}\text { GCTATTTCTCTGCGGGTCTA } \\
\text { GCTGTCAATGAAACAGATGG }\end{array}$ & 809 & Monomorphic \\
\hline RHO & GTPase rho1 & AF395859 & Unknown & $\begin{array}{l}\text { RHO36F } \\
\text { RHO685R }\end{array}$ & $\begin{array}{l}\text { AGTTATCGTTGGTGATGGAG } \\
\text { TGAAGCTCCTCAAGTGTCTT }\end{array}$ & 650 & Monomorphic \\
\hline TUB $^{\mathrm{e}}$ & $\beta$-Tubulin & AJ313150 & Wheat & $\begin{array}{l}\text { TUB210F } \\
\text { TUB1308R }\end{array}$ & $\begin{array}{l}\text { CAGGGCAAACAATTTCTGGT } \\
\text { GCTGAACATTTCGCATCTGA }\end{array}$ & 1,099 & Polymorphic \\
\hline
\end{tabular}

a Variability in eastern U.S. wheat mildew. Monomorphy based on sequencing of at least 70 U.S. isolates from diverse locations.

b GenBank accession numbers FJ747878 to FJ748080.

c GenBank accession numbers FJ748081 to FJ748283.

d GenBank accession numbers FJ748284 to FJ748486.

e GenBank accession numbers FJ747675 to FJ747877. 
Nonparametric sequence-based tests for population subdivision were applied in a hierarchical manner by the program SNAP Map (6) and two programs performing Hudson's tests, $S_{\mathrm{nn}}$ (35) and Permtest (33), using 1,000 permutations to determine a null distribution in order to assess significance of results. Because phylogenetic conflict has been reported to increase power of these tests (35), incompatibilities were included in the analysis. First, sequences from all 10 U.S. sampling locations were tested in pairwise comparisons. Each pair of two locations with no significant genetic differences between them was collapsed into a single population for subsequent tests, and then another round of pairwise comparisons was conducted. This process continued until only significantly different, geographically structured population groups remained. Population subdivision was also assessed with the model-based Bayesian clustering algorithm implemented in Structure $2.2(22,63)$ with the optimal number of populations $(K)$ empirically determined by comparing posterior distribution likelihoods among runs.

AMOVA was carried out using Arlequin (20). AMOVA is a method of partitioning genetic diversity into within-population and among-population components for detecting population differences (21). In Arlequin, a "population" was composed of the individuals sampled from a single location (e.g., 10 individuals sampled from a single field constituted one population). AMOVA requires a priori hypotheses about population structure that can be tested by aggregating multiple populations into regions. Results included variance components of each source of variation (among regions, within populations, and among populations within regions), percentage of total variation explained by each variance source, and $\Phi$ statistics with associated $P$ values. The $\Phi$ statistics are haplotype correlation coefficients: $Ф C \mathrm{~T}$ estimates variance among regions, ФSC estimates variance among populations within regions, and $\Phi S T$ estimates variance within populations across all sampled populations (21). All $\Phi$ statistics are analogous to
Wright-Fisher's Fst (21). The final population clusters found by $S_{\mathrm{nn}}$ and Structure, as well as other possible population clusters, were input as groups in Arlequin and tested via AMOVA to confirm population inferences. $P$ values computed for $\Phi$-SC, $\Phi$ ST, and $\Phi-C T$ were based on 1,023 permutations of the null distribution for each variance component and indicated the probability of obtaining by chance a result more extreme than the observed value (20).

\section{RESULTS}

Nucleotide sequence polymorphisms were detected in proteincoding portions of four $B$. graminis $\mathrm{f}$. sp. tritici genes: $\beta$-tubulin (TUB), alternative oxidase (AOX), protein kinase A (PKA), and protein phosphatase type 2A (PPA) (Table 3). Eight other genes, when sequenced in at least 70 isolates from geographically widely separated U.S. locations, were found to be nonpolymorphic. Of the four sequences with variation, 12 SNPs were identified in total, 8 of which were phylogenetically informative (Table 4). An informative single-nucleotide mutation is one that occurs in at least two haplotypes, such that one evolutionary relationship among haplotypes can be favored over the other possible relationships based on parsimony.

Amplification and sequencing of all four polymorphic regions of interest was successful with $141 \mathrm{~B}$. graminis f. sp. tritici isolates from the United States, 34 isolates from the United Kingdom, and 28 isolates from Israel. In total, there were 25 unique multilocus haplotypes (Table 4). No insertions or deletions were detected and all data were consistent with an infinite-sites model, where each variable position has only a single mutation. Within the United States, two haplotypes (H1 and H11) made up $71 \%$ of the isolates sampled. Haplotype 1 was found in all locations in the United States except Plains, GA, and haplotype 11 was found everywhere except Chocowinity, NC and Felton, DE.

TABLE 4. Distribution of Blumeria graminis f. sp. tritici haplotypes across sampling locations in the United States (US), United Kingdom (UK), and Israel (Isr)

\begin{tabular}{|c|c|c|c|c|c|c|c|c|c|c|c|c|c|c|c|}
\hline \multirow{3}{*}{ Haplotype } & \multicolumn{12}{|c|}{ Locus, consensus, character type ${ }^{a}$} & & & \\
\hline & \multicolumn{2}{|c|}{ AOX } & \multicolumn{3}{|c|}{ PKA } & \multicolumn{5}{|c|}{ PPA } & \multicolumn{2}{|c|}{ TUB } & & & \\
\hline & $\mathrm{T}$ & $\mathrm{C}$ & A & A & $\mathrm{T}$ & $\mathrm{T}$ & $\mathrm{T}$ & G & $\mathrm{C}$ & $\mathrm{C}$ & $\mathrm{T}$ & $\mathrm{C}$ & \multicolumn{3}{|c|}{ No. of isolates } \\
\hline $\mathrm{H} 3$ & . & $\mathrm{T}$ & & . & . & $\mathrm{C}$ & . & . & . & . & . & . & 2 & 0 & 0 \\
\hline H7 & . & . & $\mathrm{T}$ & . & . & $\mathrm{C}$ & . & . & . & . & . & . & 1 & 0 & 0 \\
\hline $\mathrm{H} 8$ & . & . & $\mathrm{T}$ & . & . & $\mathrm{C}$ & . & . & . & . & $\mathrm{C}$ & . & 1 & 0 & 0 \\
\hline $\mathrm{H} 13$ & . & . & . & . & A & $\mathrm{C}$ & . & . & . & . & . & G & 5 & 0 & 0 \\
\hline H14 & . & . & . & . & A & . & $\mathrm{C}$ & . & . & . & . & . & 1 & 0 & 0 \\
\hline H15 & . & . & . & . & A & . & $\mathrm{C}$ & . & . & A & $\mathrm{C}$ & 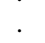 & 1 & 0 & 0 \\
\hline $\mathrm{H} 18$ & . & . & . & . & . & . & $\mathrm{C}$ & . & . & . & . & . & 3 & 0 & 0 \\
\hline $\mathrm{H} 23$ & . & . & . & . & . & & . & . & . & . & . & G & 1 & 0 & 0 \\
\hline $\mathrm{H} 25$ & . & . & . & . & . & $\mathrm{C}$ & . & . & . & . & . & $\mathrm{G}$ & 7 & 0 & 0 \\
\hline H1 & . & . & . & . & . & $\mathrm{C}$ & . & . & . & . & . & . & 60 & 0 & 3 \\
\hline H6 & . & . & $\mathrm{T}$ & . & . & . & . & . & . & . & . & . & 0 & 1 & 0 \\
\hline $\mathrm{H} 9$ & . & . & . & G & . & . & . & . & . & . & . & . & 0 & 1 & 0 \\
\hline $\mathrm{H} 10$ & . & . & . & . & A & . & . & . & . & . & $\mathrm{C}$ & . & 0 & 8 & 0 \\
\hline H17 & . & . & . & . & A & . & . & . & . & . & . & . & 0 & 5 & 0 \\
\hline $\mathrm{H} 21$ & . & . & . & . & . & . & . & . & A & . & $\mathrm{C}$ & . & 0 & 1 & 10 \\
\hline $\mathrm{H} 4$ & . & $\mathrm{T}$ & . & . & A & . & . & . & . & . & $\mathrm{C}$ & . & 0 & 0 & 1 \\
\hline H16 & . & . & . & . & A & . & . & . & A & . & $\mathrm{C}$ & . & 0 & 0 & 1 \\
\hline $\mathrm{H} 20$ & . & . & . & . & . & . & . & A & . & . & $\mathrm{C}$ & . & 0 & 0 & 1 \\
\hline Total & & & & & & & & & & & & & 141 & 34 & 28 \\
\hline
\end{tabular}

${ }^{a}$ Each locus comprises variable positions within a single nuclear gene; $\mathrm{AOX}=$ alternative oxidase, $\mathrm{PKA}=$ protein kinase $\mathrm{A}, \mathrm{PPA}=$ protein phosphatase type $2 \mathrm{~A}$, and TUB $=\beta$-tubulin. Most frequent or consensus nucleotide for each variable position: $\mathrm{T}, \mathrm{C}, \mathrm{A}$, or G. Character type indicates whether each variable position is phylogenetically informative (i) or noninformative (-). To be informative, a position must have mutations that appear in at least two haplotypes. 
All right-side neutrality tests (excess of ancient mutations) were nonsignificant and only Fu's $F$ s left-side test (excess of recent mutations or rare alleles) was significant $(F s=-15.728$, $P=0.001)$. The "A" allele in the fourth polymorphic position of PPA was phylogenetically informative and only found in the United Kingdom and Israel (Table 4). Several other U.K. and Israeli private alleles were detected; however, all were noninformative. The U.S. samples had three informative private alleles: positions one and two within PPA and position two in TUB (Table 4).

Tests for linkage disequilibrium among the four housekeeping genes found significant $\mathrm{LD}$ overall (index of association $\left[\mathrm{I}_{\mathrm{A}}\right]=$ $0.156, P<0.001)$ but, in pairwise tests of the four genes, no significant $\mathrm{LD}$ was detected $(P>0.149)$. The significant $\mathrm{I}_{\mathrm{A}}$ was likely due to the presence of a small number of high-frequency haplotypes.

The initial test with $S_{\text {nn }}$ (35) divided the U.S. population into two groups. Due to small sample size, the isolates from Princeton, KY were left out. Kinston, Warsaw, Felton, Salisbury, Chocowinity, and Painter had no significant differences among them and formed a single group (group $1, P \geq 0.223$ ). Plains, Griffin, and Headland formed group $2(P \geq 0.315)$. A further $S_{\text {nn }}$ test was then performed on the two new larger groups, each created by pooling groups not significantly different. In this test, group 1 was significantly different from group $2(P=0.007)$. The result was a putative eastern U.S. population structure of two groups designated mid-Atlantic (M) and south (S). Samples from the United Kingdom (UK) and Israel (I) were tested against each other and found to not be significantly different $(P=0.08)$. Both Old World groups were significantly different from the $\mathrm{M}$ and $\mathrm{S}$ populations of the United States (UK/M: $P \leq 0.007$; UK/S: $P \leq 0.015$; I/M: $P<0.015 ; \mathrm{I} / \mathrm{S}: P<0.016)$. Thus, three groups were detected using Hudson's tests: M, S, and Old World (O). Tests were performed for subdivision among sampled locations within the United Kingdom and Israel, respectively, but no significant differences were found, possibly due to small sample sizes.

When the entire data set was analyzed using Structure, the optimal parameter setting was the no-admixture model, in which each individual was assigned to only one population, with independent allele frequencies. The optimum number of populations $(K)$, as determined by runs with consistently higher posterior probabilities, was two: one population consisting of U.S. isolates and a second consisting of isolates from the United Kingdom and

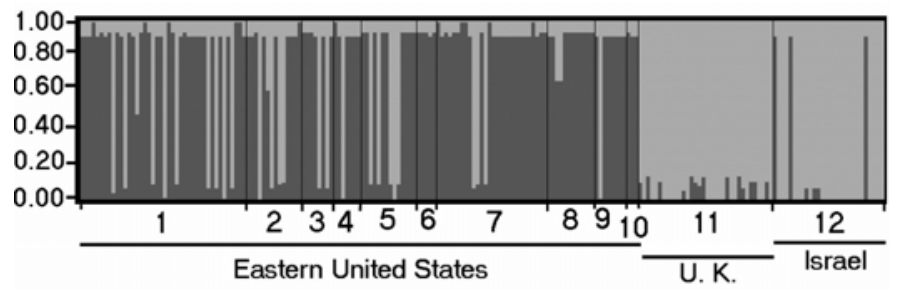

Fig. 2. Structure bar plot indicating probability (y-axis) of each isolate belonging to one of two groups. Each vertical bar is one isolate. On $\mathrm{x}$-axis, numbers are centered under populations as follows: $1=$ Kinston, NC; $2=$ Warsaw, VA; 3 = Painter, VA; 4= Felton, DE; 5= Plains, GA; 6 = Headland, $\mathrm{AL} ; 7=$ Salisbury, NC; $8=$ Griffin, GA; $9=$ Chocowinity, NC; $10=$ Princeton, KY; 11 = United Kingdom; and 12 = Israel.
Israel (Fig. 2). According to the documentation, Structure may perform better when smaller data sets are used. Therefore, independent runs were performed using only U.S. samples in an attempt to confirm divisions found with Hudson's tests. Runs using only Old World isolates were also carried out to check for divisions between Israel and the United Kingdom. In both cases, the runs with highest posterior probability yielded $K=1$, and no further differentiation could be found to confirm the Hudson's tests results in the United States.

PAUP* was unable to complete an MP heuristic search, presumably due to extensive conflict in the data set. The ML search in PAUP* produced at least seven "tree-islands," indicating that a single phylogeny based on the four combined loci was a poor representation of the data (71). A tree-island is a set of phylogenetic trees differing from one another by a single rearrangement and with likelihood scores above an arbitrary level (71). ML and MP analyses of individual genes yielded too few haplotypes to produce meaningful phylogenies, and analyses of gene pairs indicated conflict. Given these results, no phylogeny is presented. Compatibility analysis using SNAP Clade (79) identified conflicting sites between loci, supporting the theory that conflict among sites was the obstacle to completion of phylogenetic searches. CladeEx removed three conflicting sites (third variable base position in PKA, first position in PPA, and first position in TUB). Migration analysis using MDIV (57) was subsequently performed between all inferred population pairs that were significantly subdivided; however, too little phylogenetic signal was present to obtain reliable estimates of migration rates.

Several potential population structures were tested with AMOVA using Arlequin. The best population structure (the one with the smallest estimate of within-region variance among populations, or ФSC ) (16) was found to be a four-region model with M, S, UK, and I populations separated. That is, the best-fitting AMOVA model was one in which mid-Atlantic populations were grouped into one region, southern U.S. populations were grouped into a

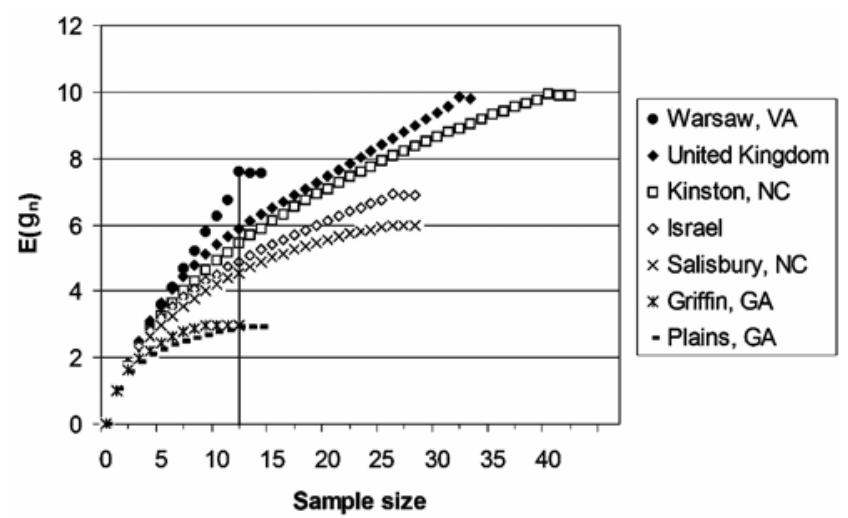

Fig. 3. Estimates of genotypic richness of Blumeria graminis f. sp. tritici population sampled in the eastern United States, the United Kingdom, and Israel. Curves are derived by rarefaction (see text for details). The vertical axis indicates richness or $\mathrm{E}\left(\mathrm{g}_{\mathrm{n}}\right)$, the expected number of genotypes found in a population of $n$ individuals, from each location. Actual sample sizes are read at the end of each curve. The vertical line at the sample size of 12 indicates the smallest number of isolates sampled at any location and is the point where populations should be compared for haplotype richness.

TABLE 5. Analysis of molecular variance for Blumeria graminis f. sp. tritici isolates from the eastern United States, the United Kingdom, and Israel

\begin{tabular}{|c|c|c|c|}
\hline Source of variance ${ }^{a}$ & Variance & Total variance $(\%)$ & $\Phi$ Statistic \\
\hline Among regions & 0.442 & 43.6 & $\Phi_{\mathrm{CT}}=0.436$ \\
\hline Among populations within regions & 0.017 & 1.7 & $\Phi_{\mathrm{SC}}=0.031$ \\
\hline Within populations across regions & 0.554 & 54.7 & $\Phi_{\mathrm{ST}}=0.453$ \\
\hline
\end{tabular}

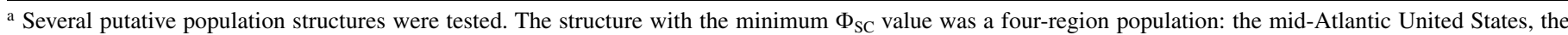
United States south, the United Kingdom, and Israel. 
second region, and the U.K and Israeli samples were each both a population and a region. The largest percentage of population variance $(54.7 \%)$ was within populations across regions and $43.6 \%$ of variance was among regions. Only $1.7 \%$ of total variance was among populations within the two U.S. regions. All $P$ values based on the distribution of the data after 1,023 permutations were significant (Table 5).

Mean genotypic diversity was moderate in our samples (Table 1). The highest genotypic diversity was found in the United Kingdom. Depending on the index, the lowest genotypic diversity was found at Headland, AL or Chocowinity, NC, but the sample sizes from these two locations were small. Diversity estimates were affected by varying sample sizes, and rarefaction curves calculated for locations with $>10$ isolates allowed more direct comparison of relative genotype richness (Fig. 3). Rarefaction results are interpreted by comparing the estimated population richness $\left[E\left(g_{n}\right)\right]$ values for all locations at the number of individuals present in the smallest sample (30). In Figure 3, the $\mathrm{E}\left(\mathrm{g}_{\mathrm{n}}\right)$ values of all samples of $>10$ individuals can be compared along the vertical line at 12, the size of the smallest sample in the comparison (Griffin, GA). In our analysis, samples from the southern United States were the least genotype-rich and samples from Warsaw and the United Kingdom were the most genotyperich.

\section{DISCUSSION}

Our study is the first to use DNA sequence polymorphisms to analyze the population structure of U.S. wheat powdery mildew and the first to compare U.S. and international isolates. The low level of nucleotide variation and the high proportion of lowfrequency haplotypes detected in the U.S. B. graminis f. sp. tritici population support the inference of recent haplotype proliferation in the eastern United States (75). These results are also consistent with a young population that underwent a bottleneck and subsequent expansion of range and population size (2), as would be expected following a host range expansion or introduction by European colonists.

As mentioned above, there are at least two possibilities for the origin of the U.S. B. graminis f. sp. tritici population. B. graminis f. sp. tritici may have been introduced from other wheat-growing regions of the world, or the pathogen may have made the jump to wheat from wild grass relatives native to the United States. Our results make the former scenario seem more likely. B. graminis $\mathrm{f}$. sp. hordei, the barley-specific powdery mildew fungus, is very closely related to $B$. graminis $\mathrm{f}$. $\mathrm{sp}$. tritici. DNA sequence similarity between the two formae speciales is 93 to $95 \%$ for the genes used in our survey, as determined by GenBank BLAST search. Given the low levels of divergence between isolates from the United States, Israel, and the United Kingdom (the two most divergent haplotypes have $>99 \%$ DNA sequence identity overall for the sequences compared), it seems likely that U.S. isolates are direct descendents of the Old World B. graminis f. sp. tritici population.

Further support for recent $B$. graminis $\mathrm{f}$. sp. tritici introduction in the United States is the significant result for Fu's Fs left-side test. Fu's $F s$ provides a test based on the model of no population growth; significant deviations from the model indicate an expanding population. The interpretation of these results must be tempered because the validity of Fu's $F s$ has not been tested in the presence of phylogenetic conflict (25), and our data set has evidence of extensive conflict between loci.

Assuming that B. graminis f. sp. tritici was introduced with wheat into the United States, it seems unlikely that conidia were the means of introduction, given their ephemerality $(15,18)$. Rather, the trans-Atlantic crossing was likely made by cleistothecia borne on wheat straw that was used for some purpose such as animal bedding (livestock arrived as early as 1607 in James- town, VA) (51). The present survey did not include the region around Texas, and thus offers no insights regarding the possibility of $B$. graminis f. sp. tritici introduction from Spanish colonization of that region. However, we are now analyzing isolates from the southern U.S. Great Plains to assess their relatedness with the eastern U.S. population. There may have been additional introductions of wheat mildew into the Atlantic states following the initial introduction, which further complicates the analysis. The overall detected trend of north-south population subdivision in the eastern United States, with a zone of demarcation approximately at North Carolina, supported by both AMOVA and Hudson's tests, could reflect roughly contemporaneous initial introductions in Texas and Virginia and subsequent population expansions into intermediate regions. Alternatively, the north-south differences we detected might be the result of isolation by distance (54) from the Virginia source alone. We were unable to obtain estimates of migration rates and directions between the mid-Atlantic and southern U.S. sampling areas due to the lack of phylogenetic signal in our data set once conflicting sites were removed.

Structure had less power to detect differentiation among populations than Hudson's tests. Structure only detected population subdivision between U.S. and Old World populations, whereas Hudson's tests found three population clusters (mid-Atlantic United States, United States south, and Old World). Structure assumes that all loci are independent, but SNPs within a contiguous DNA sequence are physically linked. Thus, Structure's lower power compared with Hudson's tests may be due to violations of the model. In any case, it should be noted that the power of Structure to detect population division may be less than that of simple permutation-based methods when dealing with DNA sequences with low divergence. The results of AMOVA and Hudson's tests were marginally different. AMOVA confirmed the division between mid-Atlantic and southern U.S. populations. However, AMOVA gave a population structure with U.K. and Israeli isolates separated in two distinct regions, whereas Hudson's tests could not distinguish them.

The AMOVA results supported differentiation of the eastern U.S. B. graminis f. sp. tritici population into mid-Atlantic and southern regions, because a very small percentage $(1.7 \%)$ of the total variance was among populations within the regions. Interestingly, the largest source of variance was not among regions, but rather within populations. This was not surprising, given that the U.K. and Israeli samples constituted a single population in our analysis. But it does indicate that a large percentage of total genetic variation among the 203 isolates from three continents was on a relatively small geographic scale, and most of the subdivision was supported by a few low-frequency haplotypes or alleles. The high-frequency haplotypes $\mathrm{H} 1$ and $\mathrm{H} 11$ were found almost throughout the U.S. region studied; therefore, it was the distribution of the remaining, rarer haplotypes that determined population subdivision in the United States.

The importance of ascospores in $B$. graminis $\mathrm{f}$. $\mathrm{sp}$ tritici epidemic initiation and population structuring has not been fully demonstrated. However, the large number of rare haplotypes in our study likely indicates that the sexual stage of B. graminis $\mathrm{f}$. sp. tritici has an important effect on the genetic structure of the U.S. powdery mildew population. This is further supported by the existence of extensive conflict in our data set as detected by the four-gamete test implemented in CladeEx (79), a result which carries more weight because this test has low power in sequences with low mutation rates (34). The loci used in this study did not appear to be in physical linkage and the sexual stage is probably the main mechanism causing conflicting gene genealogies, through either interlocus recombination or independent assortment. The prevalence of interlocus conflict in our data set and the abundance of rare haplotypes point to an important role for the sexual stage in the evolution of $B$. graminis f. sp. tritici in the eastern United States. 
What then accounts for the prevalence of just two haplotypes in our U.S. sample, haplotypes 1 and 11? Although sexual recombination likely occurs annually, rapid selection for and asexual reproduction of highly fit genotypes appear to reduce the majority of recombinant genotypes to small proportions of the population. Our finding of two dominant haplotypes is consistent with the results of barley mildew virulence and fungicide sensitivity surveys. In one survey conducted in Cambridge, UK, $\approx 40 \%$ of 88 to $100 \mathrm{~B}$. graminis f. sp. hordei isolates collected at random on each of three dates during a growing season had one of three virulence and fungicide resistance phenotypes (11). In Germany, a single race of barley mildew predominated in field and aerial samples over a 2-year period (90). These surveys were of phenotypic traits; however, it is not unreasonable to presume that the same mechanisms operate on nonselected DNA as in our case. In a virulence survey of the same isolates used in the present study, we found that $53 \%$ of 206 isolates had one of just six multilocus virulence phenotypes (59).

The deployment of susceptible cultivars should tend to encourage establishment of new haplotypes, because all pathotypes are capable of reproducing (91). Conversely, the use of mildewresistant cultivars would reduce the impact of sexual reproduction, because fewer strains can infect, survive, and mate and those that do will likely be more genetically similar. Thus, despite the fact that this pathogen is heterothallic and undergoes frequent sexual recombination, it is plausible to find two dominant haplotypes and a substantial number of low-frequency haplotypes.

Rarefaction analysis revealed that $B$. graminis $\mathrm{f}$. $\mathrm{sp}$. tritici haplotype richness was greatest in locations most conducive to wheat mildew: the United Kingdom and mid-Atlantic states of the United States (Fig. 3). Environmental conditions less hospitable to mildew likely have caused population bottlenecks, reducing genetic richness. The cooler climate of the United Kingdom is more conducive to mildew than the arid conditions of the Middle East, and haplotype richness is greater in the United Kingdom, despite the fact that the Israeli mildew isolates were collected in or near the center of origin of their hosts and, thus, might be expected to represent an ancestral and genetically more diverse population. Similarly, lower haplotype diversity in the southernmost U.S. locations (Headland, Plains, and Griffin), which are warmer earlier in the year, is logical given the relative infrequence of mildew epidemics in those regions.

Another possible explanation for greater B. graminis f. sp. tritici haplotype richness in the mid-Atlantic states would be multiple separate pathogen introductions in the area around Virginia. Virginia experienced waves of European (primarily English) colonization throughout the 17th and 18th centuries (68), which raises the possibility of multiple wheat mildew introductions. Mildew may have spread south with wheat cultivation, with bottlenecks and genetic drift occurring during range expansion. There also remains the unexplored possibility of concurrent introductions of mildew into Texas and Virginia. The resulting converging range expansions would also be consistent with lower genetic diversity in Georgia and Alabama, which are roughly equidistant from Virginia and east Texas.

Although we were unable to do so in the present study, it would be desirable to estimate migration rates of wheat mildew in the eastern United States, in order to assess the risk of rapid spread of novel virulences. As of this writing, wheat cultivars carrying the mildew resistance gene $P m 17$ remain largely effective throughout the sampling area (personal observation). However, high frequencies of Pm17-virulent isolates were detected in samples from Headland, Alabama, and Plains, GA in 2005 (59) and we would like to know whether and how fast these resistance-breaking isolates might be expected to migrate elsewhere. The broad geographic distribution of our most frequent haplotypes ( $\mathrm{H} 1$ and H11) is certainly consistent with the hypothesis of a randommating population with gene flow throughout the sampling regions. According to a report from Europe, spores of B. graminis remain viable after traveling up to $800 \mathrm{~km}$ in a single trip (32); therefore, it appears that Pm17-virulent spores could rapidly move north if wind patterns were ideal and conditions were favorable for spore survival. Given the low levels of variation detected in $B$. graminis f. sp. tritici genes, migration would be better detected using loci with higher mutation rates such as microsatellites, which we are currently developing. In addition, obtaining more polymorphic markers would likely dilute the effects of conflict between genealogies and allow phylogenetic inferences.

In summary, we found evidence to support a recent origin of the U.S. wheat powdery mildew population from the Old World. Low levels of polymorphism were detected in the U.S. B. graminis f. sp. tritici population and two haplotypes predominated across the eastern United States from Delaware to Alabama. At the same time, extensive phylogenetic conflict in the data set and the large number of rare haplotypes indicated the importance of the sexual stage in structuring the $B$. graminis f. sp. tritici population. The U.S. population was genetically distinct from the Old World populations at neutral loci, likely due to genetic drift after a small number of isolates were introduced by European colonists. The eastern U.S. population was also subdivided into mid-Atlantic and southern-state clusters, possibly arising from isolation by distance or barriers to gene flow. Our comparison of U.S., U.K., and Israeli populations revealed greater genotypic richness of $B$. graminis f. sp. tritici populations in environments where more regular disease epidemics occur, suggesting that the population undergoes recurrent and significant genetic bottlenecking in less conducive environments.

\section{ACKNOWLEDGMENTS}

Part of this work was carried out with the resources of the Computational Biology Service Unit from Cornell University, which is partially funded by Microsoft Corporation. We thank R. Bayles and A. Skellern at NIAB and A. Dinoor at the Hebrew University of Jerusalem for generously providing mildew cultures; N. Grünwald for assistance in implementing rarefaction methods, using his software; and C. Gatlin, T. Gray, P. Labadie, P. Langdon, M. Munster, and J. Patton Özkurt for excellent research and technical assistance.

\section{LITERATURE CITED}

1. Agapow, P. M., and Burt, A. 2001. Indices of multilocus linkage disequilibrium. Mol. Ecol. Notes 1:101-102.

2. Althoff, D. M., and Pellmyr, O. 2002. Examining genetic structure in a bogus Yucca moth: A sequential approach to phylogeography. Evolution 56:1632-1643.

3. Andrivon, D., and Vallavieille-Pope, C. 1993. Racial diversity and complexity in regional populations of Erysiphe graminis f. sp. hordei in France over a 5-year period. Plant Pathol. 42:443-464.

4. Avise, J. C. 2000. Phylogeography. Harvard University Press, Cambridge, MA.

5. Avise, J. C., Arnold, J., Ball, R. M., Bermingham, E., Lamb, T., Neigel, J. E., Reeb, C. A., and Saunders, N. C. 1987. Intraspecific phylogeography: The mitochondrial DNA bridge between population genetics and systematics. Annu. Rev. Ecol. Syst. 18:489-522.

6. Aylor, D. L., Price, E. W., and Carbone, I. 2006. SNAP: Combine and Map modules for multilocus population genetic analysis. Bioinformatics 22:1399-1401.

7. Beaty, T. H., Fallin, M. D., Hetmanski, J. B., McIntosh, I., Chong, S. S., Ingersoll, R., Sheng, X., Chakraborty, R., and Scott, A. F. 2005. Haplotype diversity in 11 candidate genes across four populations. Genetics 171:259-267.

8. Bermingham, E., and Mortiz, C. 1998. Comparative phylogeography concepts and applications. Mol. Evol. 7:367-369.

9. Bernatchez, L. 2001. The evolutionary history of brown trout (Salmo trutta L.) inferred from phylogeographic, nested clade, and mismatch analyses of mitochondrial DNA variation. Evolution 55:351.

10. Brown, J. K. M., and Hovmøller, M. S. 2002. Aerial dispersal of pathogens on the global and continental scales and its impact on plant disease. Science 297:537-541. 
11. Brown, J. K. M., and Wolfe, M. S. 1990. Structure and evolution of a population of Erysiphe graminis f. sp. hordei. Plant Pathol. 39:376-390.

12. Brown, T. A., Harris, D. R., Rollo, F., and Evershed, R. P. 1999. How ancient DNA may help in understanding the origin and spread of agriculture [and discussion]. Phil. Trans. R. Soc. Lond. 384:89-98.

13. Carbone, I., and Kohn, L. M. 1999. A method for designing primer sets for speciation studies in filamentous ascomycetes. Mycologia 91:553-556.

14. Carbone, I., Liu, Y.-C., Hillman, B. I., and Milgroom, M. G. 2004. Recombination and migration of Cryphonectria hypovirus 1 as inferred from gene genealogies and the coalescent. Genetics 166:1611-1629.

15. Cherewick, W. J. 1944. Studies on the biology of Erysiphe graminis DC. Can. J. Res. 22:52-86.

16. Ciampi, M. B., Meyer, M. C., Costa, M. J. N., Zala, M., McDonald, B. A., and Ceresini, P. C. 2008. Genetic structure of populations of Rhizoctonia solani anastomosis group-1 IA from soybean in Brazil. Phytopathology 98:932-941.

17. Clarke, N. P. A History of Small Grain Crops in Texas: Wheat, Oats, Barley, Rye 1582-1976.

18. Corner, E. J. H. 1935. Observations on resistance to powdery mildews. New Phytol. 34:180-200.

19. Dondlinger, P. T. 1908. The Book of Wheat: An Economic History and Practical Manual of the Wheat Industry. Orange Judd Company, New York.

20. Excoffier, L., Laval, G., and Schneider, S. 2005. Arlequin ver. 3.0: An integrated software package for population genetics data analysis. Evol. Bioinf. Online 1:47-50.

21. Excoffier, L., Smouse, P. E., and Quattro, J. M. 1992. Analysis of molecular variance inferred from metric distances among DNA haplotypes: Application to human mitochondrial DNA restriction data. Genetics 131:479-491.

22. Falush, D., Stephens, M., and Pritchard, J. K. 2003. Inference of population structure: Extensions to linked loci and correlated allele frequencies. Genetics 164:1567-1587.

23. Felsenstein, F. G., Limpert, E., and Fischbeck, G. 1991. Wheat mildew populations in the FRG and neighboring regions (1986-1988)-some aspects of their change. Pages 1-7 in: Integrated Control of Cereal Mildews: Virulence Patterns and their Change. J. H. Jorgensen, ed. Ris $\emptyset$ National Laboratory, Roskilde, Denmark.

24. Felsenstein, J. 1981. Evolutionary trees from DNA sequences: A maximum likelihood approach. J. Mol. Evol. 17:368-376.

25. Fu, Y. X. 1997. Statistical tests of neutrality of mutations against population growth, hitchhiking, and background selection. Genetics 147:915-925.

26. Fu, Y. X., and Li, W. H. 1993. Statistical tests of neutrality of mutations. Genetics 133:693-709.

27. Götz, M., and Boyle, C. 1998. Haustorial function during development of cleistothecia in Blumeria graminis f. sp. tritici. Plant Dis. 82:507-511.

28. Götz, M., Friedrich, S., and Boyle, C. 1996. Development of cleistothecia and early ascospore release of Erysiphe graminis DC. f. sp. tritici in winter wheat in relation to host age and climatic conditions. Z. Pflanzenkrankh. Pflanzenschutz 103:134-141.

29. Grünwald, N. J., Flier, W. G., Sturbaum, A. K., Garay-Serrano, E., van den Bosch, T. B. M., Smart, C. D., Matuszak, J. M., Lozoya-Saldana, H., Turkensteen, L. J., and Fry, W. E. 2001. Population structure of Phytophthora infestans in the Toluca valley region of Central Mexico. Phytopathology 91:882-890.

30. Grünwald, N. J., Goodwin, S. B., Milgroom, M. G., and Fry, W. E. 2003. Analysis of genotypic diversity data for populations of microorganisms. Phytopathology 93:738-746.

31. Hartl, D. L., and Clark, A. G. 1997. Principles of Population Genetics, 3rd ed. Sinauer Associates, Inc., Sunderland, MA.

32. Hermansen, J. E., Torp, U., and Prahm, L. P. 1978. Studies of transport of live spores of cereal mildew and rust fungi across the North Sea. Grana 17:41-46.

33. Hudson, R., Boos, D., and Kaplan, N. 1992. A statistical test for detecting geographic subdivision. Mol. Bio. Evol. 9:138-151.

34. Hudson, R., and Kaplan, N. 1985. Statistical properties of the number of recombination events in the history of a sample of DNA sequences. Genetics 111:147-164.

35. Hudson, R. R. 2000. A new statistic for detecting genetic differentiation. Genetics 155:2011-2014.

36. Inuma, T., Khodaparast, S. A., and Takamatsu, S. 2007. Multilocus phylogenetic analyses within Blumeria graminis, a powdery mildew fungus of cereals. Mol. Phylogenet. Evol. 44:741-751.

37. James, F. C., and Rathbun, S. 1981. Rarefaction, relative abundance, and diversity of avian communities. Auk 98:785-800.

38. Jevtic, R., Pribakovic, M., Stojanovic, S., and Leath, S. 1991. Screening the virulence of Erysiphe graminis DC. Ex Merat f. sp. tritici Em. Marchal in mobile nurseries. Plant Prot. 42:21-31.

39. Johnston, T. 1968. Host specialization as a taxonomic criterion. Pages
543-556 in: The Fungi: An Advanced Treatise. G. C. Ainsworth and A. S. Sussman, eds. Academic Press, New York.

40. Kimura, M. 1983. The Neutral Theory of Molecular Evolution. Cambridge University Press, Cambridge.

41. Kingman, J. F. C. 1982. The coalescent. Stochastic Processes Appl. 13:235-248.

42. Koltin, Y., and Kenneth, R. 1970. The role of the sexual stage in the oversummering of Erysiphe graminis DC. f. sp. hordei Marchal under semiarid conditions. Ann. Appl. Biol. 65:263-268.

43. Krebs, C. J. 1989. Ecological Methodology. HarperCollins Publishers, New York.

44. Leath, S. 1991. Wheat powdery mildew in the USA: Status of pathogen virulence and host resistance. Pages 22-32 in: Integrated Control of Cereal Mildews: Virulence Patterns and Their Change. J. H. Jorgensen, eds. Riso National Laboratory, Roskilde, Denmark.

45. Leath, S., and Murphy, J. P. 1985. Virulence genes of the wheat powdery mildew fungus, Erysiphe graminis f. sp tritici in North Carolina. Plant Dis. 69:905.

46. Lewontin, R. C., and Kojima, K. 1960. The evolutionary dynamics of complex polymorphisms. Evolution 14:450-472.

47. Limpert, E., Felsenstein, F. G., and Andrivon, D. 1987. Analysis of virulence in populations of wheat powdery mildew in Europe. J. Phytopathol. 120:1-8.

48. Lynch, M. 1988. Estimation of relatedness by DNA fingerprinting. Mol. Biol. Evol. 5:584-599.

49. Lynch, M., and Crease, T. 1990. The analysis of population survey data on DNA sequence variation. Mol. Biol. Evol. 7:277-394.

50. Machado, C. A., and Hey, J. 2003. The causes of phylogenetic conflict in a classic Drosophila species group. Proc. R. Soc. Lond. 270:1193-1202.

51. McDonald, J. J. 1907. Life in Old Virginia. The Old Virginia Publishing Co., Norfolk, VA.

52. Meeuse, A. D. J. 1973. Coevolution of plant hosts and their parasites as a taxonomic tool. Pages 289-316 in: Taxonomy and Ecology. V. H. Heywood, eds. Academic Press, London.

53. Mitter, C., and Brooks, D. R. 1983. Phylogenetic aspects of coevolution. Pages 65-98 in: Coevolution. D. J. Futuyma and M. Slatkin, eds. Sinauer Associates, Sunderland, MA.

54. Morton, N. E., Miki, C., and Yee, S. 1968. Bioassay of population structure under isolation by distance. Am. J. Hum. Genet. 20:411-419.

55. Namuco, L. O., Coffman, W. R., Bergstrom, G. C., and Sorrells, M. E. 1987. Virulence spectrum of the Erysiphe graminis f. sp. tritici population in New York. Plant Dis. 71:539-541.

56. Nei, M. 1987. Molecular Evolutionary Genetics. Columbia University Press, New York.

57. Nielsen, R., and Wakeley, J. 2001. Distinguishing migration from isolation: A Markov chain Monte Carlo approach. Genetics 158:885-896.

58. Niewoehner, A. S., and Leath, S. 1998. Virulence of Blumeria graminis f. sp. tritici on winter wheat in the eastern United States. Plant Dis. 82:6468

59. Parks, R., Carbone, I., Murphy, J. P., Marshall, D., and Cowger, C. 2008. Virulence structure of the eastern U.S. wheat powdery mildew population. Plant Dis. 92:1074-1082.

60. PAUP*. Phylogenetic Analysis Using Parsimony (*and Other Methods). Version 4. Sinauer Associates, Sunderland, MA

61. Persaud, R. R., and Lipps, P. E. 1995. Virulence genes and virulence gene frequencies of Blumeria graminis f. sp. tritici in Ohio. Plant Dis. 79:494499.

62. Price, E. W., and Carbone, I. 2004. SNAP: Workbench management tool for evolutionary population genetic analysis. Bioinformatics 21:402-404.

63. Pritchard, J. K., Stephens, M., and Donnelly, P. 2000. Inference of population structure using multilocus genotype data. Genetics 155:945959.

64. Raper, J. R. 1968. On the evolution of fungi. Pages 677-693 in: The Fungi: An Advanced Treatise. G. C. Ainsworth and A. S. Sussman, eds. Academic Press, New York.

65. Rosenberg, N. A., and Nordborg, M. 2002. Genealogical trees, coalescent theory and the analysis of genetic polymorphisms. Nat. Rev. Genet. 3:380-390.

66. Rozas, J., Sanchez-Delbarrio, J. C., Messeguer, X., and Rozas, R. 2003 DnaSP, DNA polymorphism analyses by the coalescent and other methods. Bioinformatics 19:2496-2497.

67. Rozen, S., and Skaletsky, H. J. 2000. Primer3 on the WWW for general users and for biologist programmers. Pages 365-386 in: Bioinformatics Methods and Protocols: Methods in Molecular Biology. S. Krawetz and S. Misener, eds. Humana Press, Totowa, NJ.

68. Rubin, L. D. 1977. Virginia: A Bicentennial History. W. W. Norton \& Co., New York.

69. Russell, E. J. 1934. The history of wheat in Great Britain. Nature 134:606.

70. Salamini, F., Özkan, H., Brandolini, A., Schäfer-Pregl, R., and Martin, W. 
2002. Genetics and geography of wild cereal domestication in the Near East. Nat. Rev. Genet. 3:429-441.

71. Salter, L. A. 2001. Complexity of the likelihood surface for a large DNA dataset. Syst. Biol. 50:970-978.

72. Sander, H. L. 1968. Marine benthic diversity: A comparative study. Am. Nat. 102:243-282.

73. Savile, D. B. O. 1954. The fungi as aids in the taxonomy of the flowering plants. Science 120:583-585.

74. Slatkin, M. 1994. Linkage disequilibrium in growing and stable populations. Genetics 137:331-336.

75. Slatkin, M., and Hudson, R. 1991. Pairwise comparisons of mitochondrial DNA sequences in stable and exponentially growing populations. Genetics 129:555-562.

76. Slovakova, T., Svec, M., and Miklovicova, M. 2004. Do geographical barriers play any role in isolation of powdery mildew populations? Biologia (Bratislava) 59:121-126.

77. Smedegård-Petersen, V. 1967. Studies on Erysiphe graminis DC. with a special view to the importance of the perithecia for attacks on barley and wheat in Denmark. K. Vet. Landbohoejsk. Årsskr. 77:1-28.

78. Smith, D. 1968. Classification of several native North American grasses as starch or fructosan accumulators in relation to taxonomy. Grass Forage Sci. 23:306-309.

79. SNAP Clade and Matrix, Version 2. Distributed over the Internet. Department of Plant Pathology, North Carolina State University, Raleigh.

80. Sprague, R. 1950. Diseases of Cereals and Grasses in North America. Ronald Press Company, New York.

81. Stoddart, J. A., and Taylor, J. F. 1988. Genotypic diversity: Estimation and prediction in samples. Genetics 118:705-711.

82. Stukenbrock, E. H., Banke, S., Javan-Nikkhah, M., and McDonald, B. A. 2007. Origin and domestication of the fungal wheat pathogen Mycosphaerella graminicola via sympatric speciation. Mol. Biol. Evol. 24:398-411.
83. Svec, M., and Miklovicova, M. 1998. Structure of populations of wheat powdery mildew (Erysiphe graminis DC. f. sp. tritici Marchal) in Central Europe in 1993-1996: I. Dynamics of virulence. Eur. J. Plant. Pathol. 104:537-544.

84. Tajima, F. 1989. Statistical method for testing the neutral mutation hypothesis. Genetics 123:585-595.

85. Tavare, S. 1984. Line-of-descent and genealogical processes and their applications in population genetics models. Theor. Popul. Biol. 26:119164.

86. Templeton, A. R. 1998. Nested clade analyses of phylogeographic data: Testing hypotheses about gene flow and population history. Mol. Ecol. 7:381-397.

87. Templeton, A. R., Routman, E., and Philips, C. A. 1995. Separating population structure from population history: A cladistic analysis of the geographical distribution of mitochondrial DNA haplotypes in the tiger salamander, Ambystoma tigrinum. Genetics 140:767-782.

88. Turner, D. M. 1956. Studies on cereal mildew in Britain. Trans. Br. Mycol. Soc. 39:495-506.

89. Watterson, G. A. 1975. On the number of segregating sites in genetical models without recombination. Theor. Popul. Biol. 7:256-276.

90. Welz, G., and Kranz, J. 1987. Effects of recombination on races of a barley powdery mildew population. Plant Pathol. 36:107-113.

91. Wolfe, M. S., and McDermott, J. M. 1994. Population genetics of plant pathogen interactions: The example of the Erysiphe graminis-Hordeum vulgare pathosystem. Annu. Rev. Phytopathol. 32:89-113.

92. Wolfe, M. S., and Schwarzbach, E. 1978. Patterns of race changes in powdery mildews. Annu. Rev. Phytopathol. 16:159-180.

93. Wyand, R. A., and Brown, J. K. M. 2003. Genetic and forma specialis diversity in Blumeria graminis of cereals and its implications for hostpathogen co-evolution. Mol. Plant Pathol. 4:187-198.

94. Zohary, D., Harlan, J. R., and Vard, A. 1969. The wild diploid progenitors of wheat and their breeding value. Euphytica 18:58-65. 